\title{
Nuclear instrumentation in VENUS-F
}

\author{
J. Wagemans, L. Borms, A. Kochetkov, A. Krása, C. Van Grieken, G. Vittiglio
}

Abstract-VENUS-F is a fast zero power reactor with $30 \mathrm{wt} \%$ $\mathrm{U}$ fuel and $\mathrm{Pb} / \mathrm{Bi}$ as a coolant simulator. Depending on the experimental configuration, various neutron spectra (fast, epithermal, and thermal islands) are present. This paper gives a review of the nuclear instrumentation that is applied for reactor control and in a large variety of physics experiments. Activation foils and fission chambers are used to measure spatial neutron flux profiles, spectrum indices, reactivity effects (with positive period and compensation method or the MSM method) and kinetic parameters (with the Rossi-alpha method). Fission chamber calibrations are performed in the standard irradiation fields of the BR1 reactor (prompt fission neutron spectrum and Maxwellian thermal neutron spectrum).

Index Terms - Activation, calibration, fast reactor, fission chamber, neutrons, reactor instrumentation

\section{INTRODUCTION}

$\mathrm{V}$ ENUS is a zero power reactor that is in operation at the Belgian Nuclear Research Centre SCK •CEN since 1964. Until 2007 VENUS was a thermal, water moderated reactor that mostly served as a mock-up for PWR and BWR reactors. Many configurations have been investigated and published which served to validate nuclear data and calculation codes.

In the frame of lead-based fast reactor and accelerator driven system research, and in particular for the MYRRHA project [1], VENUS was transformed to a mock-up of a fast reactor (VENUS-F) that can be operated in critical and sub-critical mode. For the latter, the GENEPI-3C accelerator was installed at SCK $\cdot \mathrm{CEN}$. This work was performed within the GUINEVERE program (2008-2011) [2] and the FREYA project (2011-2016) [3].

This paper starts with a brief presentation of the VENUS-F facility. The main focus is on the different types of instrumentation that is used for the reactor control and for performing the large variety of experiments. The importance of accurate detector calibration and the importance of the support of MCNP calculations is indicated.

\section{THE VENUS-F FACILITY}

The VENUS-F reactor is placed in an open-top stainless steel cylindrical vessel that contains a $12 \times 12$ square lattice of assemblies with a pitch of $8 \mathrm{~cm}$. The lattice is surrounded with

Submitted on 10/07/2017. This work was supported by the following projects of the European Commission: 6th EURATOM Framework Programme Integrated Project EUROTRANS (under the Contract F16W-CT-2005516520), the 7th FP FREYA project (No. 269665), and Horizon 2020 MYRTE project (Contract No. GA 662186). a bottom, top and radial lead reflector, see Fig. 1.

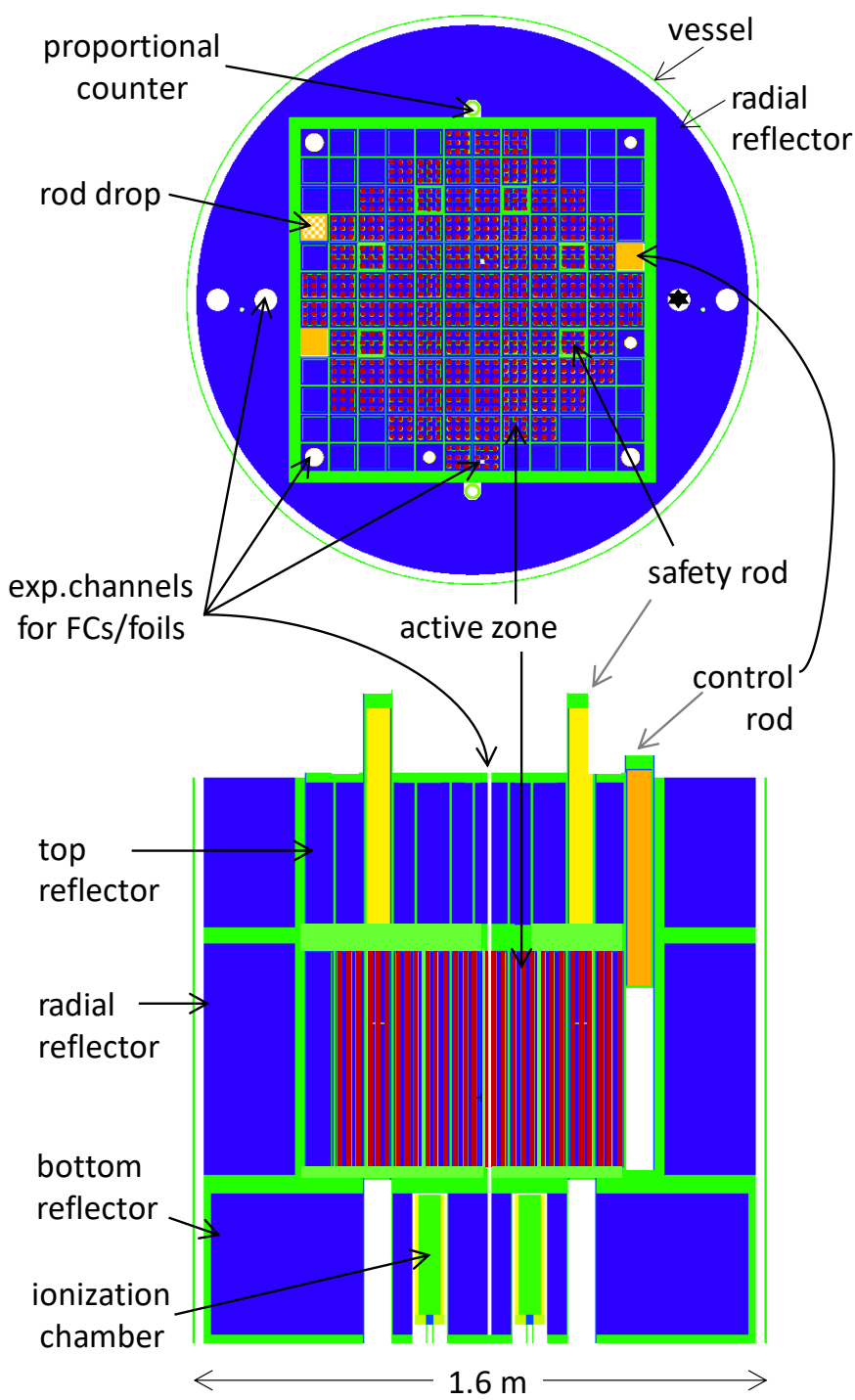

Fig. 1. Horizontal (top) and vertical (bottom) cut through the VENUS-F reactor (an example of a critical configuration). Lead - blue, uranium - red, stainless steel - green, $\mathrm{B}_{4} \mathrm{C}$ - yellow (safety rod) and orange (control rod), white - air. An $\mathrm{AmBe}$ source is indicated with a star.

Each assembly can be filled with fuel, reflector material $(\mathrm{Pb}$ or C), $\mathrm{B}_{4} \mathrm{C}$ (safety/control rod, rod drop) or any other material (e.g. PE acting as a thermal spectrum in-pile section). An assembly can contain a guiding tube and serve as an

All the authors are with the Belgian Nuclear Research Centre SCK $• \mathrm{CEN}$, Boeretang 200, Mol, 2400, Belgium (e-mail of the corresponding author: jwagemans@ sckcen.be). 
experimental assembly with a channel for insertion of detectors. A guiding tube penetrates through the top reflector and the entire length of an assembly. In certain positions, a guiding tube can run through the bottom reflector as well, see bottom part of Fig. 1.

The composition of a fuel assembly is variable. It consists of a $5 \times 5$ grid of rods: fuel rods (30 wt $\%$ metallic uranium) and coolant simulator rods (solid $\mathrm{Pb}$ or $\mathrm{Bi}$ ). Optionally, $\mathrm{Al}_{2} \mathrm{O}_{3}$ rods (for simulating oxide fuel) and experimental channels are inserted instead of fuel or coolant rods, see Fig. 2.

Thanks to the VENUS-F versatility in both the composition of the fuel assembly as well as the assembly loading pattern, four types of a fuel assembly have been loaded at VENUS-F so far and nine core configurations have reached criticality [3]. For each critical configuration, a variety of experimental channels in fuel assemblies, reflector assemblies, in-pile sections and even in the radial reflector outside the assembly lattice have been exploited, see top part of Fig. 1.

Additionally, a large number of subcritical VENUS-F configurations with the GENEPI-3C accelerator inserted in the middle of the core has been investigated. These are published elsewhere [5]-[6].

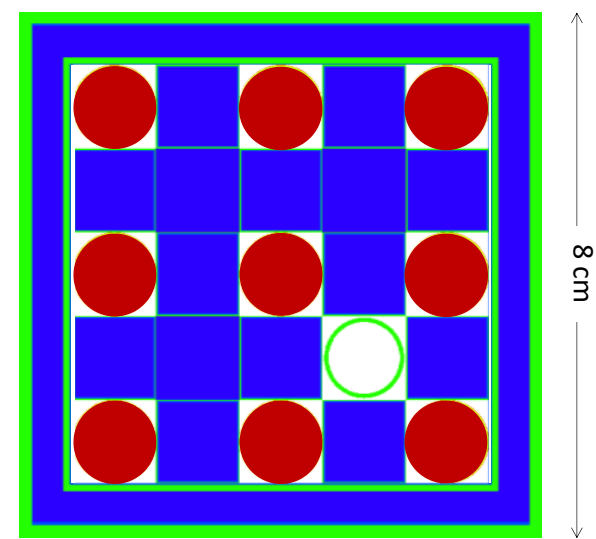

Fig. 2. Horizontal cut through an experimental fuel assembly with one rod replaced by a guiding tube. Lead - blue, stainless steel - green, uranium -red, white - air.

\section{INSTRUMENTATION}

VENUS-F is equipped with standard instrumentation for reactor control, which remains constantly loaded, and specific instrumentation for physics experiments, which are activation foils and fission chambers inserted in different experimental channels depending on the purpose of the experimental campaign.

\section{A. Instrumentation for reactor control}

To monitor the neutron flux during fuel loading and reactor startup, two $\mathrm{BF}_{3}$ proportional counters are used. $\mathrm{BF}_{3}$ gas $(90$ $w t \%$ enriched in ${ }^{10} \mathrm{~B}$ ) acts as proportional gas and neutron detection material, see Table 1 . To increase the probability of neutron detection in ${ }^{10} \mathrm{~B}$, the $\mathrm{BF}_{3}$ tubes are surrounded by a polyethylene moderator ( 4 or $8 \mathrm{~mm}$ thick cylinders). The impact of the local neutron moderation on the reactor core is insignificant because the $\mathrm{BF}_{3}$ counters are located in the radial reflector outside the assembly lattice, see top part of Fig. 1.
As VENUS-F is a zero-power reactor, the burnup is negligible and its fuel remains fresh. The neutron flux from spontaneous fission is thus not sufficient for a reliable startup. Every VENUS-F reactor startup is driven by an external AmBe source (intensity of $2 \times 10^{6}$ neutrons/s), which can be inserted in the radial reflector, see top part of Fig. 1.

For monitoring the reactor power during normal operation, four ionization chambers (PNI 1089 type supplied by Plessey) are placed in the bottom reflector, see bottom part of Fig. 1. The ionization chambers have $94 \mathrm{wt} \%$ enriched ${ }^{10} \mathrm{~B}$ deposit and hydrogen filling gas, see Table 1 . Two of them are connected to linear current chains, whereas the other two are connected to logarithmic current chains. The signals are used for example to the reactor period determination.

For monitoring the course of temperature in the core, thermocouples are connected to $\mathrm{Pb}$ or $\mathrm{Bi}$ rods in fuel assemblies. Typically, a temperature increase of $4 \mathrm{~K}$ is detected after $7 \mathrm{~h}$ of reactor operation at $100 \mathrm{~W}$ [7].

TABLE I

INSTRUMENTATION FOR THE VENUS-F REACTOR CONTROL

\begin{tabular}{ccc}
\hline \hline & Proportional counters & Ionization chambers \\
\hline Type & $\begin{array}{c}\text { 12EB40 (20th Century } \\
\text { Electronics Ltd) }\end{array}$ & PNI 1089 (Plessey) \\
Body & $\mathrm{Cu}$ & $\begin{array}{c}\text { Al, electrodes coated } \\
\text { with } 94 \mathrm{wt} \%{ }^{10} \mathrm{~B}\end{array}$ \\
Diameter & $25 \mathrm{~mm}$ & $63.5 \mathrm{~mm}$ \\
Length & $210 \mathrm{~mm}$ & $342.9 \mathrm{~mm}$ \\
Filling gas & $\mathrm{BF}_{3},>90 \mathrm{wt} \%{ }^{10} \mathrm{~B}$ & $\mathrm{H}$ \\
Active length & $120 \mathrm{~mm}$ & $193 \mathrm{~mm}$ \\
Voltage & $2400 \mathrm{~V}$ & $400-600 \mathrm{~V}$ \\
Neutron Sensitivity & $3(\mathrm{cts} / \mathrm{s}) /\left(\mathrm{n} / \mathrm{cm}^{2} / \mathrm{s}\right)$ & $2.10-14 \mathrm{~A} /\left(\mathrm{n} / \mathrm{cm}^{2} / \mathrm{s}\right)$ \\
\hline \hline
\end{tabular}

\section{B. Fission Chambers}

A large number of fission chambers is available at VENUSF. The fission chambers vary in deposit type and mass, see Table 2 . The low-mass ( $10 \mu \mathrm{g}-1 \mathrm{mg})$ fission chambers are mainly applied for measuring spatial neutron flux profiles [7] and spectrum indices [8]. The fissile deposits include ${ }^{234} \mathrm{U},{ }^{235} \mathrm{U}$, ${ }^{238} \mathrm{U},{ }^{237} \mathrm{~Np},{ }^{239} \mathrm{Pu},{ }^{240} \mathrm{Pu},{ }^{242} \mathrm{Pu}$ and ${ }^{241} \mathrm{Am}$. The detector calibrations are performed in the standard irradiation fields of the $\mathrm{BR} 1$ reactor at $\mathrm{SCK} \cdot \mathrm{CEN}$ [9]. An example of a fission fragment spectrum obtained with a low-mass fission chamber is shown in Fig. 3.

The fission chambers with heavy deposits (up to $1 \mathrm{~g}{ }^{235} \mathrm{U}$, ${ }^{238} \mathrm{U}$ ) are applied for measurements of reactivity effects (using the MSM method [10]), kinetic parameters (using the Rossialpha method [11]) and sub-criticality measurements [5],[6].

All fission chambers are operated in pulse mode. A Programmable High Speed Pulse Amplifier (PHSPA) electronic unit and a Labview-based data acquisition developed at SCK $\bullet \mathrm{CEN}$ are used. PHSPA contains several amplifier functions (current mode pre-amplifier, amplifier), filters, discriminators, counter, and an integrated high voltage source (up to $2 \mathrm{kV}$ ). A complete measurement chain can be 
realized using only this amplifier module and a PC.

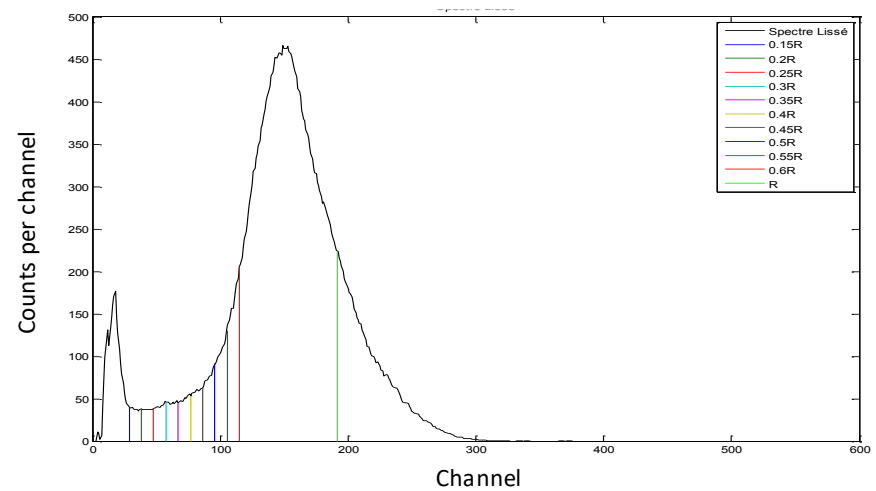

Fig. 3. Fission fragment spectrum measured with a low-mass ${ }^{235} \mathrm{U}$ fission chamber $(90 \mu \mathrm{g})$.

TABLE II

FISSION CHAMBERS FOR VENUS-F EXPERIMENTS

\begin{tabular}{|c|c|c|}
\hline & \multicolumn{2}{|c|}{ Fission chambers } \\
\hline Application & $\begin{array}{l}\text { Spatial fission rate } \\
\text { distrubutions, } \\
\text { spectrum indices }\end{array}$ & $\begin{array}{l}\text { Reactivity effects, } \\
\text { kinetic parameters, } \\
\text { control rod calibration, } \\
\text { sub-criticality }\end{array}$ \\
\hline Manufacturer & CEA, Centronic & Photonis, Reuter-Stokes \\
\hline Deposit mass [mg] & $\sim 0.01-1$ & $\begin{array}{c}\sim 1 \text { (CFUF34), } \\
10 \text { s(CFUM21), } 100 \\
\text { (RS), } 1000 \text { (CFUL01) }\end{array}$ \\
\hline $\begin{array}{l}\text { Deposit } \\
\text { isotope }\end{array}$ & $\begin{array}{l}{ }^{234,235,238} \mathrm{U},{ }^{237} \mathrm{~Np} \\
{ }^{239,240,242} \mathrm{Pu},{ }^{241} \mathrm{Am}\end{array}$ & ${ }^{235} \mathrm{U},{ }^{238} \mathrm{U}$ \\
\hline Active length [mm] & $10-25$ & $27 ; 120 ; 127 ; 211$ \\
\hline Filling gas & $\mathrm{Ar} / \mathrm{N}$ & $\mathrm{Ar} / \mathrm{N}$ \\
\hline Body & Ti, steel & $\mathrm{Al}$ \\
\hline Diameter [mm] & $1.5 ; 4 ; 8$ & $4.7 ; 26 ; 48$ \\
\hline Length $[\mathrm{mm}]$ & $23 ; 75$ & $85 ; 165 ; 227 ; 337$ \\
\hline Voltage [V] & $300-500$ & 700 \\
\hline
\end{tabular}

\section{Activation foils}

Activation dosimetry is a standard technique to determine neutron flux and fluence and to obtain information on the neutron spectrum. At $\mathrm{SCK} \cdot \mathrm{CEN}$ a laboratory equipped with high-purity Germanium detectors is situated in the same building as the BR1 and VENUS-F research reactors, which allows fast gamma spectrometry measurements without the need for transport of the activated foils. For standard situations specific activities can be determined with an uncertainty $(1 \sigma)$ lower than $2 \%$.

A set of foils with different energy responses can be used for comparison with neutronics calculations or for spectrum unfolding to obtain information on the neutron spectrum. Such stack of foils consists for example of $\mathrm{Au}, \mathrm{Al}$ and $\mathrm{In}$, and can be irradiated in the experimental fuel assemblies of VENUS-F.

Uranium foils are of particular interest for core characterization measurements in VENUS-F. Different types of foils varying in size, shape, thickness and enrichment are available for experiments. These foils can be used to determine absolute ${ }^{235} U(n, f)$ and ${ }^{238} U(n, f)$ fission rates, for example to be included in the set of foils for spectrum unfolding, to determine the ${ }^{238} \mathrm{U}(\mathrm{n}, \gamma) /{ }^{235} \mathrm{U}(\mathrm{n}, \mathrm{f})$ and ${ }^{238} \mathrm{U}(\mathrm{n}, \mathrm{f}) /{ }^{235} \mathrm{U}(\mathrm{n}, \mathrm{f})$ spectrum indices, and to determine fission rate profiles in the reactor.

When absolute values from fission foil irradiations are required (for example for spectrum index measurements), it may be necessary to correct for fission product escape. Indeed the fragments produced in fission events occurring near the foil surface have a certain probability to escape from the foil. As a consequence the measured specific activity of such foil will be lower than the expected specific activity for a given incident neutron flux. This problem can be avoided by encapsulating the fission foil in e.g. Al during its irradiation and performing the activity measurement on the foil with its encapsulation. When encapsulation is not possible, the correction has to be determined. For metallic uranium foils of about $0.1 \mathrm{~mm}$ the correction is of the order of $3 \%$. This was experimentally determined by irradiating a uranium foil sandwiched between so-called catcher foils (Al) and measuring fission products in all foils.

\section{REFERENCES}

[1] Van den Eynde et al., "MYRRHA design revision 1.6 and the phased implementation plan," in Proc. TCADS-3, Mito, Japan, 6-9 Sep 2016, pp. 141-150.

[2] P. Baeten et al., "The GUINEVERE project at the VENUS facility", in Proc. PHYSOR-2008, Interlaken, Switzerland, 14-19 Sep 2008.

[3] A. Kochetkov et al., "The Lead-Based VENUS-F Facility: Status of the FREYA Project", EPJ Web of Conferences 106, 06004 (2016).

[4] A. Krása et al., "The VENUS-F reactor for nuclear data validation", in Proc. ISRD-16, Santa Fe, USA, May 7-12, 2017.

[5] V. Bécares et al., "Reactivity determination and monitoring in FREYA Project subcritical cores: Assessment and correction of spatial and energy effects," in Proc. TCADS-3, Mito, Japan, 6-9 Sep 2016, pp. 234251.

[6] T. Chevret et al., "Spatial effects during beam interruption experiments for ADS subcriticality monitoring using a Monte Carlo alpha-mode expansion of the neutron flux," in Proc. TCADS-3, Mito, Japan, 6-9 Sep 2016, pp. 252265.

[7] A. Krása et al., "Comparative study of nuclear data libraries on Monte Carlo modelling of MYRRHA mockup critical cores in the VENUS-F reactor," in Proc. ND-2016, Brugges, Belgium, Sep 12 - 162016.

[8] A. Kochetkov et al., "Extensive analysis of $\mathrm{C} / \mathrm{E}$ results of fission rates ratios measurements in several fast lead VENUS-F cores.” in Proc. ND-2016, Brugges, Belgium, Sep $12-162016$.

[9] J. Wagemans et al., "The 235U prompt fission neutron spectrum in the BR1 reactor at $\mathrm{SCK} \cdot \mathrm{CEN}, " E P J W e b$ of Conferences 106, 06003, 2016.

[10] J.L. Lecouey et al., "Estimate of the reactivity of the VENUS-F subcritical configuration using a Monte Carlo MSM method," Annals of Nuclear Energy 83 (2015) 6575.

[11] X. Doligez et al., "Effective delayed neutron fraction measurement in the critical VENUS-F reactor using noise techniques," in Proc. ANIMMA-2015, Lisbon, Portugal, 20-24 April 2015, DOI: 10.1109/ANIMMA.2015.7465614. 